\title{
Consumers' risk perception of vegetables in Southeast Asia: Evidence from Laos, Cambodia, and Viet Nam
}

Thich Van Nguyen a, Thanh Mai Ha ${ }^{\text {* }}$, Sayvisene Boulom c, Pisidh Voe d, Chauch Heang e, Duc Anh Ha ${ }^{\mathrm{f}}$, Lytoua Chialue $^{\mathrm{c}}$, Bun Bor ${ }^{\mathrm{e}}$, Sian Phommaluesac, and Dien Huong Pham ${ }^{\text {a }}$

a Faculty of Business Administration, Banking University, Ho Chi Minh City, Viet Nam

$b$ Faculty of Economics and Rural Development, Vietnam National University of Agriculture, Hanoi, Viet Nam

c Faculty of Agriculture, National University of Laos, Lao PDR

d Mean Chey University, Sisophon, Cambodia

e Provincial Department of Agriculture Forestries and Fisheries, Siem Reap, Cambodia

$f$ Viet Nam Ministry of Health, Hanoi, Viet Nam

* Corresponding author. Email: hathanhmai@vnua.edu.vn

\section{ABSTRACT}

Vegetable safety is a public concern in Laos, Cambodia, and Viet Namdeveloping countries in Southeast Asia. Eliminating this concern requires insight into factors shaping it. Food risk perception might differ among countries due to the dissimilarities in culture, social, and economic conditions. However, an understanding on this difference is lacking in Southeast Asia. This paper is the first attempt to compare factors influencing risk perception of vegetables in Laos, Cambodia, and Viet Nam. Principle component analysis and ordered logit regression were employed on a sample of 1,199 consumers from the three countries. We found trust and perception of hazards influence risk perception across countries. Gender shaped risk perception in Laos and Viet Nam. The importance of vegetables and risk information determines risk perception in Viet Nam only, while hazard knowledge and homegrown vegetables are found to be predictors of risk perception solely in Cambodia. Since Laos, Cambodia, and Viet Nam are inhomogeneous in risk perception, policy measures to address food risk perception should be tailored to each country.

\section{INTRODUCTION}

The prevalence of food-borne outbreaks has drawn attention to food safety issues in Southeast Asia. In this region, food-borne illnesses have caused sickness in 150 million people and death in 175 thousand people, which occupied about $42 \%$ of the global death toll (World Health Organization [WHO], 2015). Food safety is even more problematic in Laos, Cambodia, and Viet Nam, and which are considered developing countries in Southeast Asia. This is due to the lack of food safety knowledge along food chains, limited resources for food safety surveillance, and poor enforcement of regulations. Subsequently, consumers in these countries are very concerned about food safety (Chadwick, Otte, \& Roland-Holst, 2008, World Bank, 2017). Food safety concerns reflect low consumer confidence in food, which might lead to negative societal and economic effects in Laos, Cambodia, and Viet Nam. In order to solve the problem, it is important to gain insight into consumer self-assessment of food safety risk.

\section{KEYWORDS}

Determinants, developing countries, food safety, risk perception, Southeast Asia, vegetables

\section{DOI}

https://doi.org/10.30852/sb.2020.1130

\section{DATES}

Received: 27 December 2019

Published (online): 11 September 2020

Published (PDF): 20 October 2020

This work is licensed under a Creative Commons Attribution-NonCommercial 4.0 International License.

\section{HIGHLIGHTS}

» Risk perception of vegetables was considerably high and varies across Laos, Cambodia, and Viet Nam.

» Trust and perception of hazards determine risk perception in all selected countries.

» Other factors influencing risk perception differed among the three countries.

» Interventions to address heightened food risk perception should be tailored to each country. 
This paper focuses on risk perception of vegetables in Laos, Cambodia, and Viet Nam. Risk perception of vegetables is a subjective evaluation of the health risk associated with contaminated vegetables. Among different contamination sources of vegetables, pesticide residue is the biggest challenge in these countries, as there is ample evidence of pesticide overuse in vegetable production (Schreinemachers et al., 2017). Since studies on risk perception of food, including vegetables, are scant in Laos and Cambodia, it is unclear how Laotians and Cambodians perceive vegetable risk. Some surveys in Viet Nam show that consumers rate vegetables as the riskiest common food due to concerns about pesticide residue (Ha, Shakur, \& Pham Do, 2019, Figuié, Bricas, Thanh, Truyen, \& de l'Alimentation, 2004). Besides hazard concerns, little is known about other factors influencing risk perception of vegetables. This paper will address these research gaps.

The objective of this paper is to compare the determinants of vegetable risk perception among Laos, Cambodia, and Viet Nam. Previous literature has established some key predictors of food risk perception. Individuals tend to lower risk perception when they trust in institutions (Hobbs \& Goddard, 2015) and feel that they

\begin{tabular}{|c|c|c|c|c|c|c|c|c|c|}
\hline \multirow[t]{2}{*}{ Variables } & \multicolumn{3}{|c|}{$\begin{array}{l}\text { Whole sample } \\
(n=1199)\end{array}$} & \multicolumn{2}{|l|}{$\begin{array}{l}\text { Laos } \\
(n=328)\end{array}$} & \multicolumn{2}{|c|}{$\begin{array}{l}\text { Cambodia } \\
(n=300)\end{array}$} & \multicolumn{2}{|c|}{$\begin{array}{l}\text { Vietnam } \\
(n=571)\end{array}$} \\
\hline & Mean & $S D$ & $\begin{array}{l}\text { [Min- } \\
\text { Max] }\end{array}$ & Mean & $S D$ & Mean & $S D$ & Mean & $S D$ \\
\hline Vegetable Risk Perception & 3.56 & 0.90 & {$[1-5]$} & $3.43^{\mathrm{a}}$ & 0.91 & $3.41^{\mathrm{a}}$ & 0.81 & $3.72^{\mathrm{b}}$ & 0.93 \\
\hline \multicolumn{10}{|l|}{ Hazard Knowledge } \\
\hline - Pesticide & 2.75 & 1.16 & {$[1-5]$} & $3.25^{\mathrm{a}}$ & 1.15 & $2.01^{\mathrm{b}}$ & 0.96 & $2.85^{c}$ & 1.06 \\
\hline - Bacteria & 2.61 & 1.06 & {$[1-5]$} & $2.95^{\mathrm{a}}$ & 1.00 & $2.02^{\mathrm{b}}$ & 0.88 & $2.74^{\mathrm{c}}$ & 1.06 \\
\hline - Heavy metal & 2.17 & 1.14 & {$[1-5]$} & $2.71^{\mathrm{a}}$ & 1.21 & $1.32^{\mathrm{b}}$ & 0.64 & $2.31^{\mathrm{c}}$ & 1.06 \\
\hline - GMO & 1.93 & 1.04 & {$[1-5]$} & $2.25^{\mathrm{a}}$ & 1.07 & $1.38^{\mathrm{b}}$ & 0.65 & $2.04^{c}$ & 1.08 \\
\hline \multicolumn{10}{|l|}{ Hazard Perception } \\
\hline - Pesticide & 3.98 & 0.86 & {$[1-5]$} & $3.96^{\mathrm{a}}$ & 0.84 & $3.92^{\mathrm{a}}$ & 0.65 & $4.02^{\mathrm{a}}$ & 0.97 \\
\hline - Bacteria & 3.64 & 0.91 & {$[1-5]$} & $3.48^{\mathrm{a}}$ & 0.81 & $3.48^{\mathrm{a}}$ & 0.78 & $3.82^{\mathrm{b}}$ & 0.99 \\
\hline - Heavy metal & 3.75 & 0.95 & {$[1-5]$} & $3.40^{\mathrm{a}}$ & 0.87 & $3.61^{\mathrm{b}}$ & 0.75 & $4.02^{c}$ & 1.01 \\
\hline - GMO & 3.54 & 1.08 & {$[1-5]$} & $3.18^{\mathrm{a}}$ & 0.92 & $3.46^{\mathrm{b}}$ & 0.91 & $3.78^{\mathrm{c}}$ & 1.18 \\
\hline \multicolumn{10}{|l|}{ Risk Information } \\
\hline$-\mathrm{TV}$ & 3.20 & 1.05 & {$[1-5]$} & $3.03^{\mathrm{a}}$ & 0.97 & $2.55^{\mathrm{b}}$ & 0.88 & $3.65^{c}$ & 0.97 \\
\hline - Social media & 3.22 & 1.26 & {$[1-5]$} & $3.32^{\mathrm{a}}$ & 1.34 & $2.64^{\mathrm{b}}$ & 1.11 & $3.48^{\mathrm{a}}$ & 1.20 \\
\hline - Word of mouth & 3.11 & 1.07 & {$[1-5]$} & $2.85^{\mathrm{a}}$ & 1.03 & $3.07^{\mathrm{b}}$ & 1.03 & $3.29^{c}$ & 1.09 \\
\hline \multicolumn{10}{|l|}{ Institutional Trust } \\
\hline - Farmer & 2.25 & 0.90 & {$[1-5]$} & $2.64^{\mathrm{a}}$ & 0.83 & $2.64^{\mathrm{a}}$ & 0.70 & $1.83^{\mathrm{b}}$ & 0.97 \\
\hline - Retailer & 2.25 & 0.94 & {$[1-5]$} & $2.57^{\mathrm{a}}$ & 0.77 & $2.14^{\mathrm{b}}$ & 0.65 & $2.14^{\mathrm{b}}$ & 1.11 \\
\hline - Government & 2.93 & 0.93 & {$[1-5]$} & $3.44^{\mathrm{a}}$ & 0.79 & $2.76^{\mathrm{b}}$ & 0.83 & $2.40^{\mathrm{c}}$ & 1.26 \\
\hline Children $^{1}$ & 1.01 & 1.01 & {$[0-6]$} & $1.13^{\mathrm{a}}$ & 1.03 & $1.12^{\mathrm{a}}$ & 1.14 & $0.87^{\mathrm{b}}$ & 0.91 \\
\hline Age & 39.54 & 13.08 & {$[18-78]$} & $43.96^{\mathrm{a}}$ & 11.80 & $42.55^{\mathrm{a}}$ & 13.50 & $35.42^{\mathrm{b}}$ & 12.28 \\
\hline Education $^{2}$ & 2.62 & 1.46 & {$[0-6]$} & $2.18^{\mathrm{a}}$ & 1.34 & $1.44^{\mathrm{b}}$ & 1.17 & $3.49^{c}$ & 1.06 \\
\hline Gender $^{3}$ & 0.21 & 0.43 & {$[0-1]$} & $0.33^{\mathrm{a}}$ & 0.47 & $0.07^{\mathrm{b}}$ & 0.26 & $0.21^{\mathrm{c}}$ & 0.41 \\
\hline LogIncome $^{4}$ & 2.46 & 0.29 & {$[0.9-3.7]$} & $2.39^{\mathrm{a}}$ & 0.28 & $2.51^{\mathrm{b}}$ & 0.27 & $2.47^{\mathrm{c}}$ & 0.29 \\
\hline Vegetable Importance 5 & 4.08 & 0.80 & {$[1-5]$} & $3.95^{\mathrm{a}}$ & 0.75 & $4.11^{\mathrm{b}}$ & 0.53 & $4.14^{\mathrm{b}}$ & 0.92 \\
\hline Vegetable Poisoning ${ }^{6}$ & 0.52 & 1.55 & {$[0-1]$} & $0.36^{\mathrm{a}}$ & 1.08 & $0.82^{\mathrm{b}}$ & 2.61 & $0.44^{\mathrm{a}}$ & 0.88 \\
\hline Home grown ${ }^{7}$ & 0.55 & 0.5 & {$[0-1]$} & $0.77^{a}$ & 0.42 & $0.40^{\mathrm{b}}$ & 0.49 & $0.50^{\mathrm{b}}$ & 0.50 \\
\hline
\end{tabular}

TABLE 1. Descriptive statistics of selected variables.

Note: a,b,c: different superscripts denote statistically different mean scores at 5\% level using ANOVA analysis and Tukey's post hoc test. 1: number of children; 2: education level is from 1 (no schooling) to 6 (postgraduate); 3 : gender = 1 if male; 4: logarithmic monthly income in USD; 5 : perception of the importance of vegetables in the diet; 6 : number of times the respondent has experienced vegetable poisoning in the last 2 years; 7: homegrown $=1$ if the household is growing vegetables. 
are knowledgeable about food hazards (Siegrist, 2000). In contrast, perception of the danger of food hazards (Cheng et al., 2016) and information about food incidents (Wachinger, Renn, Begg, \& Kuhlicke, 2013) increase risk perception. According to Douglas and Wildavsky (1983), risk perception was a social or cultural construct. Laos, Cambodia, and Viet Nam are different in regards to food safety management, economic development, and social and cultural settings. Risk perception of vegetables and its determinants, therefore, might vary among these countries. This paper is the first cross-country analysis of food safety risk perception in Asian developing countries. The paper will advance our understanding of food risk perception and provide evidence-based solutions to address food safety concerns in Asian developing countries.

\section{METHODOLOGY}

The study used data from our consumer survey conducted in Laos, Cambodia, and Viet Nam in 2019. The survey was conducted in six large cities including Vientiane and Savannakhet (Laos), Phnom Penh and Siem Reap (Cambodia), and Hanoi and Ho Chi Minh City (Viet Nam). A total of 1,199 main food shoppers comprising of 571 Vietnamese, 328 Laotians, and 300 Cambodians were randomly surveyed in the mentioned cities.
Table 1 shows the dependent variables and their potential explanators that have been well established in previous literature. Vegetable Risk Perception, the dependent variables were originally measured by a 5-point Likert scale. It was then transformed into a 3-point scale: 1 (low risk), 2 (medium risk), and 3 (high risk) for better interpretation of regressions. We employed ordered logit regression that is suitable for ordinal variables. Our survey revealed a high level of vegetable risk perception in the surveyed countries, particularly in Viet Nam (mean score of 3.56 for the whole sample, of 3.7 for Viet Nam, Table 1).

Hazard Knowledge (self-reported knowledge of hazards), Hazard Perception (perception about the danger of hazards), Risk Information (information acquisition about food incidents), and Trust are constructs that were measured by 14 items in total. Some correlation coefficients of these items were in the range from 0.5 to 0.7. Hence, Principle Component Analysis (PCA) was employed to transform this 14 -item dataset into fewer uncorrelated components that preserve most of the information of the dataset (Jolliffe, 2002). ANOVA analysis shows that most of the mean scores of the items were statistically significantly different among Laos, Cambodia, and Viet Nam (Table 1). This suggests that the datasets of selected countries were inhomogeneous.

\begin{tabular}{|c|c|c|c|c|c|c|c|c|c|c|c|c|}
\hline \multirow[b]{2}{*}{ 1. Knowledge of hazards } & \multicolumn{4}{|c|}{ Laos } & \multicolumn{4}{|c|}{ Cambodia } & \multicolumn{4}{|c|}{ Viet Nam } \\
\hline & 1 & 2 & 3 & 4 & 1 & 2 & 3 & 4 & 1 & 2 & 3 & 4 \\
\hline Pesticide & .802 & & & & .742 & & & & .819 & & & \\
\hline Bacterial & .854 & & & & .789 & & & & .844 & & & \\
\hline Heavy metal & .772 & & & & .853 & & & & .859 & & & \\
\hline GMO & .772 & & & & .737 & & & & .768 & & & \\
\hline \multicolumn{13}{|l|}{ 2. Perception of hazards } \\
\hline Pesticide & & .674 & & & & .629 & & & & .786 & & \\
\hline Bacterial & & .762 & & & & .750 & & & & .858 & & \\
\hline Heavy metal & & .746 & & & & .836 & & & & .900 & & \\
\hline GMO & & .739 & & & & .848 & & & & .764 & & \\
\hline \multicolumn{13}{|l|}{ 3. Trust } \\
\hline Farmer & & & .782 & & & & .821 & & & & .761 & \\
\hline Food retailer & & & .817 & & & & .756 & & & & .693 & \\
\hline Government & & & .665 & & & & .715 & & & & .764 & \\
\hline \multicolumn{13}{|l|}{ 4. Risk Information } \\
\hline TV & & & & .782 & & & & .704 & & & & .693 \\
\hline Internet & & & & .416 & & & & .791 & & & & .732 \\
\hline Word of mouth & & & & .657 & & & & .626 & & & & .745 \\
\hline Total variance explained (\%) & \multicolumn{4}{|c|}{58.148} & \multicolumn{4}{|c|}{64.092} & \multicolumn{4}{|c|}{63.773} \\
\hline KMO value & \multicolumn{4}{|c|}{0.663} & \multicolumn{4}{|c|}{0.726} & \multicolumn{4}{|c|}{0.717} \\
\hline
\end{tabular}

TABLE 2. PCA results. Note: The rotation method is Varimax with Kaiser Normalization. 
PCA, therefore, was applied separately for each country. Components retained from PCA must have eigenvalue that is equal to, or larger than 1 (Jolliffe, 2002). Retained components and the last 8 variables in Table 1 were then regressed for each subsample.

\section{RESULTS AND DISCUSSION}

\subsection{Results of PCA}

All subsamples had significant Bartlett's tests and acceptable Kaiser-Meyer-Olkin (KMO), which was higher than the threshold of 0.5 (Field, 2013). These two indicators confirmed the suitability of the datasets to PCA. Four selected components were Hazard Knowledge, Hazard Perception, Trust, and Risk Information.

\subsection{Results of ordered logit regression}

A consistent result among three subsamples was the significant effect of trust and perception of hazards. The effect of other variables on risk perception tends to differ across countries. "Education" was only significant in Cambodia, while "Gender" determined risk perception in Viet Nam and Laos but not Cambodia. Homegrown vegetables and knowledge of hazards influenced vegetable risk perception in Cambodia only. Risk information and perception about the importance of vegetables in the diet shaped risk perception in Viet Nam but not in the other two countries.

\subsection{Discussion}

Trust is one of the two common determinants of risk perception across Laos, Cambodia, and Viet Nam.
Consumers face difficulties in assessing food safety (Unnevehr et al., 2010). Holding personal trust in the government and others helps them reduce the complexity of food safety judgment, resulting in decreased risk perception of vegetables. Consistent with a survey in China (Chen, 2013), this paper confirms the role of trust in shaping food safety risk perception. Since trust in all institutions was low (Table 1), improving trust is one of the measures to address safety concerns in Laos, Cambodia, and Viet Nam.

Perception of hazards is another common predictor of vegetable risk evaluation in all studied countries. Consumers viewed all food hazards highly dangerous (mean scores from 3.56 to 3.9, Table 1). This view led to the perception that vegetable consumption is associated with high health risks. Noticeably, consumers perceived a larger threat from chemical hazards (pesticides, heavy metals), as compared to biological hazards (bacteria) (Table 1). However, according to WHO (2015), it is not chemical but biological hazards that are the main cause of food-borne illness in Southeast Asia. Consumers in our survey might be biased in hazard perception, which can cause a misinterpretation about vegetable risk.

Laos, Cambodia, and Viet Nam differed in some other factors influencing risk perception. Together with Taylor et al. (2012), we found that women perceived higher vegetable risk than men in Laos and Viet Nam. Women occupied about $70 \%$ and $80 \%$ of the sample in Laos and Viet Nam, respectively. Women are more responsive in ensuring household food safety. They act as a gatekeeper in selecting and preparing food for their families (Lin, 1995). Probably because of this role, risk perception was higher for women. This finding implies that women

\begin{tabular}{|l|l|l|l|l|l|l|}
\hline \multirow{2}{*}{ Variables } & \multicolumn{2}{l}{ Laos $(\mathrm{n}=328)$} & \multicolumn{2}{l|}{ Cambodia $(\mathrm{n}=300)$} & \multicolumn{2}{l}{ Vietnam $(\mathrm{n}=571)$} \\
\cline { 2 - 7 } & Coef. & SE & Coef. & SE & Coef. & SE \\
\hline Children & -0.134 & 0.107 & -0.094 & 0.116 & -0.013 & 0.104 \\
\hline Age & -0.011 & 0.011 & -0.004 & 0.011 & -0.006 & 0.009 \\
\hline Education & -0.010 & 0.099 & $0.303^{* *}$ & 0.135 & 0.066 & 0.104 \\
\hline Gender & $-0.570^{* *}$ & 0.239 & -0.779 & 0.528 & $-0.692^{* * *}$ & 0.217 \\
\hline LogIncome & -0.471 & 0.393 & 0.856 & 0.572 & 0.507 & 0.217 \\
\hline Homegrown & 0.038 & 0.263 & $-1.336^{* * *}$ & 0.278 & -0.114 & 0.184 \\
\hline Vegetable Importance & 0.159 & 0.147 & 0.336 & 0.269 & $0.238^{* *}$ & 0.101 \\
\hline Vegetable Poisoning & 0.025 & 0.147 & -0.053 & 0.056 & 0.237 & 0.111 \\
\hline Hazard Knowledge & 0.060 & 0.115 & $0.732^{* * *}$ & 0.162 & 0.223 & 0.095 \\
\hline Hazard Perception & $0.462^{* * *}$ & 0.114 & $0.291^{* *}$ & 0.132 & $0.443^{* * *}$ & 0.090 \\
\hline Trust & $-0.238^{* *}$ & 0.111 & $-0.565^{* * *}$ & 0.142 & $-0.160^{*}$ & 0.090 \\
\hline Risk Information & 0.056 & 0.111 & -0.189 & 0.147 & $0.236^{* *}$ & 0.096 \\
\hline McKelvey \& Zavoina's R2: & 10.40 & & 39.40 & & 16.80 & \\
\hline
\end{tabular}

TABLE 3. Ordered logit regression results. Note: *, **, *** denotes significant level at $10 \%, 5 \%$ and $1 \%$, respectively. 
should be the target group of risk communication initiatives in Laos and Viet Nam.

Risk information determined risk perception in Viet Nam only. Risk perception is formed through a process of seeking, receiving, and processing information (Roberts et al., 2016). According to Ha et al. (2019), Vietnamese' exposure to intensive information about food safety incidents from mass media has given rise to food safety risk perception. Hence, adequate risk communication is needed to form Vietnamese consumers' unbiased food risk perception. Only in the Viet Nam subsample, perceived importance of vegetables shaped vegetable risk perception. Our survey revealed that vegetables were an essential cuisine for Vietnamese, as the mean score of "vegetable importance" is 4.2 out of 5 (Table 2). This suggests a high product involvement associated with vegetables in this country. Based on the perceived importance of vegetables and its positive relationship with risk perception, we recommend that better management of vegetable safety is urgently needed.

The presence of homegrown vegetables reduced the risk perceived of vegetables in Cambodia. There is a common belief that homegrown food is far safer than marketed alternatives (Green, Draper, \& Dowler, 2003). Cambodian consumers who have homegrown vegetables, therefore, perceived a lower risk from their vegetable consumption. This paper highlights that supporting the self-provision of food in big cities in Cambodia would lower concern about food safety. In Cambodia, knowledge of hazards increased with vegetable risk perception. We previously expected that knowledge of hazards, a proxy of perceived control over food safety, would negatively affect risk perception of vegetables. However, our finding contradicts our previous expectation. More research is needed to retest the influence of food safety knowledge on risk perception in Southeast Asia.

\section{CONCLUSIONS}

Consumers in Laos, Cambodia, and Viet Nam perceive a considerably high level of vegetable safety risk. Reducing food risk perception is crucial due to its adverse impact on food consumption. This requires a better understanding of factors determining risk perception in these countries that have been ignored in previous studies. Using data from a survey of 1,199 consumers, we found that Laos, Cambodia, and Viet Nam have two similar determinants of vegetable risk perception: trust and knowledge of hazards. These countries were different regarding other predictors of risk perception. Risk perception was higher for females in Laos and Viet Nam. Results show that the importance of vegetables in the diet, and risk information shaped risk perception in
Viet Nam but not in the other two countries, and hazard knowledge and the presence of homegrown vegetables affected risk perception only in Cambodia. From a policy perspective, addressing public concerns over vegetable safety in developing countries in Southeast Asia will require an improvement of consumers' knowledge of food hazards and institutional trust. However, since some factors shaping food risk perception vary among the three countries, risk communication should be country-specific. Heightened risk perception can generate a profound impact on food consumption. If vegetable safety is not managed properly, loss for the domestic vegetable sector is unavoidable in developing countries in Southeast Asia.

\section{ACKNOWLEDGEMENT}

We appreciate the funding from the AsiaPacific Network for Global Change for the project CRRP2018-10SY-Nguyen.

\section{REFERENCES}

Chadwick, K., Otte, J. \& Roland-Holst, D. (2008). Information failure in livestock market: evidence from Lao PDR. Pro-Poor Livestock Policy Initiative.

Chen, W. (2013). The effects of different types of trust on consumer perceptions of food safety. China Agricultural Economic Review, 5(1), 43-65. doi:10.1108/17561371311294757

Cheng, L., Jiang, S., Zhang, S., You, H., Zhang, J., Zhou, Z., ... Shang, K. (2016). Consumers' behaviors and concerns on fresh vegetable purchase and safety in Beijing urban areas, China. Food Control, 63, 101-109. doi:10.1016/j.foodcont.2015.11.024

Douglas, M. \& Wildavsky, A. (1983). Risk and culture: An essay on the selection of technological and environmental dangers, Univ of California Press.

Field, A. (2013). Discovering statistics using IBM SPSS statistics, Sage.

Figuié, M., Bricas, N., Thanh, V. P. N., Truyen, N. D., \& de l'Alimentation, E. S.-E. (2004). Hanoi consumers' point of view regarding food safety risks: an approach in terms of social representation. Vietnam Social Sciences, 3, 63-72.

Green, J., Draper, A., \& Dowler, E. (2003). Short cuts to safety: Risk and "rules of thumb" in accounts of food choice. Health, Risk \& Society, 5(1), 33-52. doi:10.1080/1369857031000065998

Ha, T. M., Shakur, S., \& Pham Do, K. H. (2019). Consumer concern about food safety in Hanoi,Vietnam. Food Control, 98, 238-244. doi:10.1016/j. foodcont.2018.11.031

Hobbs, J. E., \& Goddard, E. (2015). Consumers and 
trust. Food Policy, 52, 71-74. doi:10.1016/j. foodpol.2014.10.017

Jolliffe, I. T. (2002). Principle Component Analysis, Second Edition, Springer. doi:10.1007/b98835

Lin, C.-T. J. (1995). Demographic and Socioeconomic Influences on the Importance of Food Safety in Food Shopping. Agricultural and Resource Economics Review, 24(2), 190-198. doi:10.1017/s1068280500008832

Roberts, S. M., Grattan, L. M., Toben, A. C., Ausherman, C., Trainer, V. L., Tracy, K., \& Morris, J. G. (2016). Perception of risk for domoic acid related health problems: A cross-cultural study. Harmful Algae, 57, 39-44. doi:10.1016/j.hal.2016.03.007

Schreinemachers, P., Chen, H., Nguyen, T. T. L., Buntong, B., Bouapao, L., Gautam, S., ... Srinivasan, R. (2017). Too much to handle? Pesticide dependence of smallholder vegetable farmers in Southeast Asia. Science of The Total Environment, 593-594, 470-477. doi:10.1016/j.scitotenv.2017.03.181

Siegrist, M. (2000). The Influence of Trust and Perceptions of Risks and Benefits on the Acceptance of Gene Technology. Risk Analysis, 20(2), 195-204. doi:10.1111/0272-4332.202020

Taylor, A. W., Coveney, J., Ward, P. R., Dal Grande, E., Mamerow, L., Henderson, J., \& Meyer, S. B. (2012).
The Australian Food and Trust Survey: Demographic indicators associated with food safety and quality concerns. Food Control, 25(2), 476-483. doi:10.1016/j. foodcont.2011.11.003

Unnevehr, L., Eales, J., Jensen, H., Lusk, J., McCluskey, J., \& Kinsey, J. (2010). Food and Consumer Economics. American Journal of Agricultural Economics, 92(2), 506-521. doi:10.1093/ajae/aaq007

Wachinger, G., Renn, O., Begg, C., \& Kuhlicke, C. (2012). The Risk Perception Paradox-Implications for Governance and Communication of Natural Hazards. Risk Analysis, 33(6), 1049-1065. doi:10.1111/j.1539-6924.2012.01942.x

World Health Organization. (2015). WHO estimates of the global burden of foodborne diseases: foodborne disease burden epidemiology reference group 2007-2015, World Health Organization.

World Bank. (2017). Food safety risk management in Vietnam: Challenges and opportunities: technical working paper. Hanoi, Vietnam: World Bank. World Bank. Access March 5, 2019, from https://www. worldbank.org/en/country/vietnam/publication/ food-safety-risk-management-in-vietnam-challenges-and-opportunities 